\title{
MELHORIA DA QUALIDADE DO PRODUTO ATRAVÉS DA APLICAÇÃO DE UMA GEOMETRIA DE MOLDE CHANFRADA*
}

\author{
Franz Ramstorfer ${ }^{1}$ \\ Eduardo Manzano ${ }^{2}$ \\ Nízia Mendes Fonseca ${ }^{3}$ \\ Carlos Augusto Saraiva de Maria ${ }^{4}$
}

\section{Resumo}

No lingotamento contínuo, o molde de cobre, onde ocorre a solidificação primária, é um dos componentes principais que determinam a estabilidade do processo e a qualidade superficial das placas. Durante as últimas décadas, vários formatos das placas estreitas do molde foram desenvolvidos para reduzir a ocorrência de trincas transversais nos cantos das placas, de modo a melhorar a qualidade e o rendimento do produto final laminado. Placas estreitas do molde com um chanfro foram aplicadas com sucesso à produção na Máquina de Lingotamento 4 da Usiminas / Cubatão. Aspectos do desenho das placas de molde e da aplicação prática delas, bem como o impacto da aplicação na qualidade do produto final laminado são abordados. A inspeção visual dos produtos laminados após a linha de decapagem mostrou que a ocorrência de defeitos de superfície nas bordas pode ser reduzida significativamente com a utilização da geometria de molde chanfrada.

Palavras-chave: Molde de lingotamento contínuo; Geometria de molde chanfrada.

\section{IMPROVEMENT OF THE PRODUCT QUALITY THROUGH THE APPLICATION OF CHAMFERED MOLD GEOMETRY}

\begin{abstract}
In continuous casting, the copper mold, where the primary solidification occurs, is one of the key components which determine the process stability and the surface quality of slabs. During the last decades, several mold narrow face shapes were developed in order to reduce the occurrence of transverse corner cracks of slabs and to enhance the quality and the yield of the final rolled product. Lateral mold plates with a chamfer have been successfully applied to production at Continuous Caster 4 of Usiminas / Cubatão. Aspects of the design of the mold plates and their practical application as well as the impact of the application to the quality of the final rolled product are addressed. The visual inspection of the rolled products after the pickling line showed that the occurrence of surface defects at the borders could be reduced significantly by using chamfered mold geometry.
\end{abstract}

Keywords: Continuous casting mold; Chamfered mold geometry.

Engenheiro Mecânico, Ph.D., Especialista de processos, Usiminas, Cubatão, SP, Brasil.

Engenheiro Mecânico, Coordenador de manutenção, Usiminas, Cubatão, SP, Brasil.

Engenheira Metalurgista, Engenheira de produto, Usiminas, Cubatão, SP, Brasil.

Técnico Metalurgista, Assistente técnico industrial, Usiminas, Cubatão, SP, Brasil. 


\section{INTRODUÇÃO}

No lingotamento contínuo de produtos planos, os cantos resfriam mais rápido do que as quatro superfícies do veio. Isso é em particular um problema quando as temperaturas de canto atingem a faixa de baixa ductilidade do aço lingotado ( 950 $720^{\circ} \mathrm{C}$ ), o que provoca a fragilidade dessas regiões de canto e, consequentemente, há uma maior probabilidade da geração de defeitos de superfície durante o desempeno do veio. Nessa condição de lingotamento, provocada quando a velocidade de lingotamento é baixa, trincas transversais de canto são formadas no fundo das marcas de oscilação no canto do veio, devido à concentração de tensões, e propagam-se durante o processo de desempeno atingindo até $20 \mathrm{~mm}$ de comprimento. Aços microligados de alta resistência são particularmente propensos à formação deste tipo de trincas. Tirolet et al [1], Quingshen et al [2] e Derda et al [3] abordam além do mecanismo de formação deste tipo de trinca, a influência da composição química do aço na probabilidade de ocorrência de trinca transversal de canto.

Se não forem detectadas durante a inspeção das placas e não forem removidas através da escarfagem das quinas, as trincas geram defeitos do tipo "Esfoliação Metálica" no produto final laminado. Contramedidas comuns para evitar a formação das trincas de canto nas placas são: a) Otimização dos parâmetros de oscilação para reduzir a profundidade das marcas de oscilação; b) Otimização do resfriamento secundário através da distribuição de água dos bicos de sprays e da quantidade de água; c) Otimização da composição química do aço lingotado.

É também conhecido que a aplicação de geometrias alternativas de moldes de lingotamento contínuo tem uma influência significativa na formação de trincas nos blocos e placas. Durante as últimas décadas, vários formatos de placas estreitas do molde foram desenvolvidos para reduzir a ocorrência de trincas transversais nos cantos das placas e melhorar a qualidade e o rendimento do produto final laminado. Wimmer [4] dá uma visão ampla dos diferentes conceitos e da aplicação para lingotamento contínuo de placas e blocos. Ao contrário da geometria de veio convencional sem chanfro, onde o calor dos cantos é extraído de duas superfícies perpendiculares ao mesmo tempo, a geometria chanfrada proporciona uma extração de calor substancialmente mais homogênea, pois o calor é retirado apenas de uma superfície tangencial. Assim, é possível manter a temperatura dos cantos acima da faixa de baixa ductilidade do aço lingotado durante o processo de desempeno do veio e evitar a ocorrência das trincas transversais de canto. Adicionalmente, 0 ângulo de canto maior reduz a concentração de tensão na parte inferior no fundo das marcas de oscilação no canto do veio e mostra também vantagens durante 0 processo de laminação. Patrick e Thornton [5] mostram em detalhe a aplicação de placas estreitas do molde com um chanfro de $40 \times 40 \mathrm{~mm}$ para lingotamento de placas.

O objetivo do presente trabalho é a aplicação de placas estreitas do molde com um chanfro à produção na Máquina de Lingotamento 4 da Usiminas / Cubatão. Aspectos do desenho das placas de molde e da aplicação prática delas, bem como o impacto da aplicação na qualidade do produto final laminado são abordados.

\section{MATERIAIS E MÉTODOS}

O projeto das placas de molde estreitas chanfradas foi iniciado de forma conservadora, pois uma mudança significativa na concepção destas placas, que 
também inclui as canaletas do resfriamento primário, pode trazer enormes efeitos negativos relativos à segurança de operação, qualidade do produto e produtividade da máquina como rompimentos de veio, defeitos superficiais das placas, paradas de máquina não desejadas, entre outros. O chanfro incorporado nas placas estreitas do molde com $210 \mathrm{~mm}$ de largura é mostrado nas figuras 1 (a) e (b). Devido á política interna de confidencialidade, não pode ser informada as dimensões exatas das placas utilizadas.

(a)

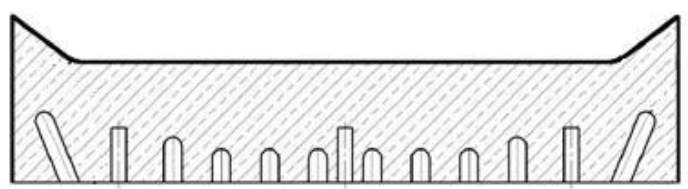

(b)

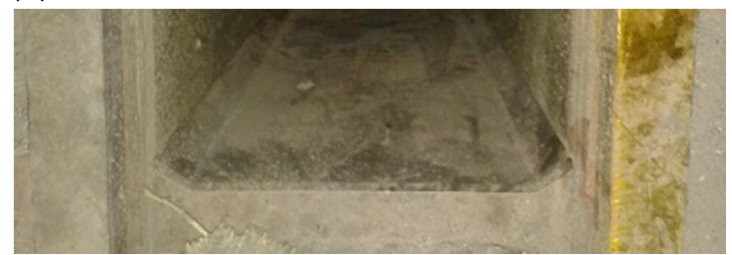

Figura 1. Seção transversal (a) e fotografia (b) da placa estreita do molde chanfrada.

O chanfro aplicado neste trabalho se diferencia do chanfro utilizado por Tirolet et al. [1] por ser menor e ter um maior ângulo $\left(>45^{\circ}\right)$ do canto exterior. A vantagem de um ângulo de canto ligeiramente maior é que a possibilidade de uma deformação da região chanfrada, devido às temperaturas ou forças excessivas que podem causar um rompimento de veio devido à infiltração de aço líquido entre a placa larga e a placa estreita, é menor.

A fim de manter a temperatura dos chanfros em um nível aceitável, a eficiência do resfriamento na zona de canto teve que ser melhorada através do aumento da profundidade das canaletas na região do chanfro. A otimização da profundidade e distribuição das canaletas, através de uma simulação térmica computacional, foi conduzida pelo fornecedor das placas, KME. Baseado nos resultados da simulação numérica, a vazão de água de resfriamento não foi alterada em relação às placas sem chanfro.

Para minimizar o desgaste, as placas de cobre foram revestidas com níquel na face principal e nas faces estreitas e, adicionalmente, a face principal foi revestida com um material cerâmico. Do ponto de vista operacional, apenas as placas extremas da cabeça da barra falsa foram modificadas conforme a figura 2 para evitar uma colisão entre as placas estreitas do molde e da barra falsa.
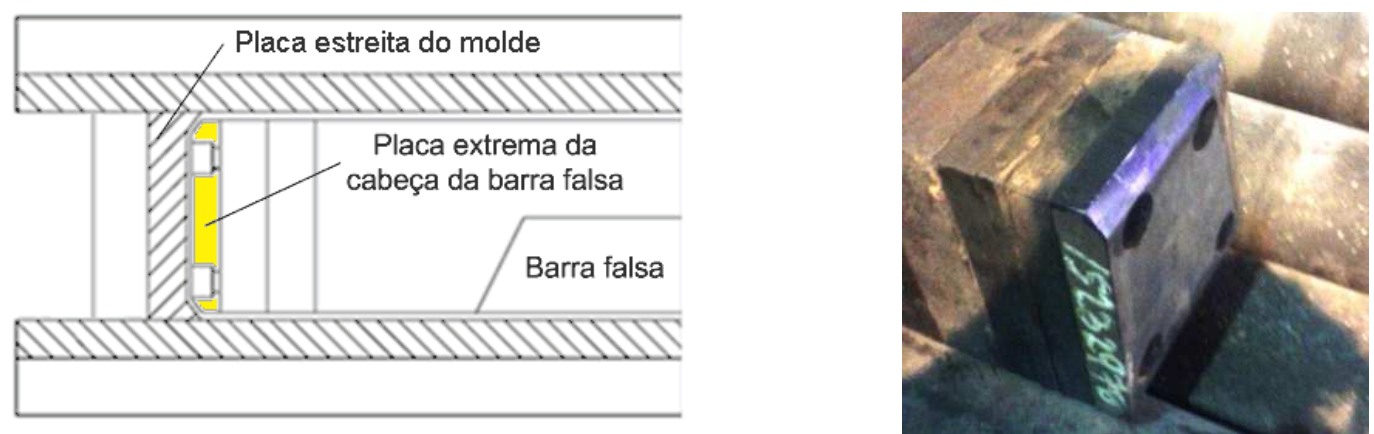

Figura 2. Modificação das placas extremas da cabeça da barra falsa para evitar a colisão entre a cabeça da barra falsa e as placas estreitas do molde chanfrado.

A usinagem das placas extremas foi feita de modo que a distância entre a cabeça da barra falsa e o molde fosse mantida constante em torno da circunferência para selagem. 


\section{RESULTADOS E DISCUSSÃO}

$\mathrm{Na}$ fase inicial de aplicação das placas estreitas do molde com chanfro, três testes separados foram realizados na Máquina de Lingotamento 4 da Usiminas / Cubatão. Essa máquina foi escolhida por ser uma máquina de dois veios, que permite uma comparação direta entre a configuração do molde original e a configuração modificada. A figura 3 mostra uma placa lingotada com a utilização das placas estreitas do molde com chanfro.

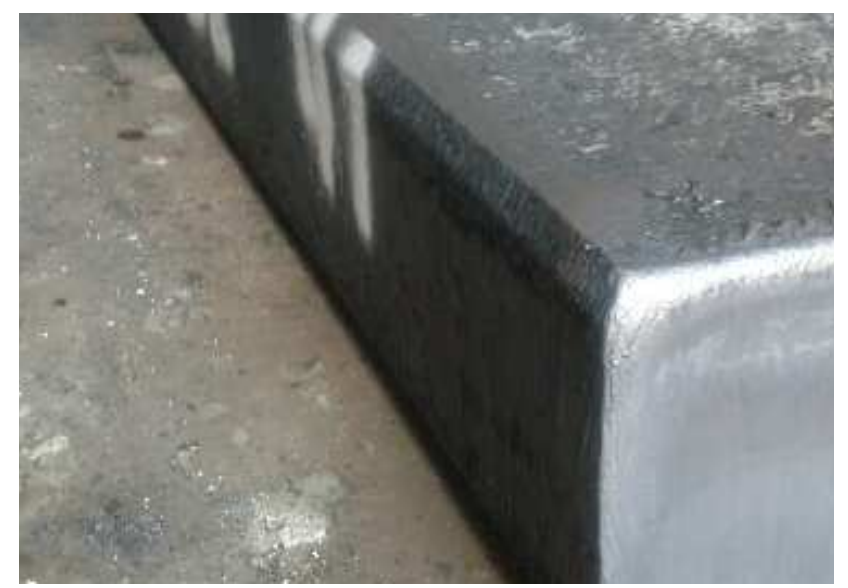

Figura 3. Placa lingotada com cantos chanfrados.

Durante essa fase inicial de aplicação foram lingotadas 18 sequências de 140 corridas $(21.196 \mathrm{t})$ no total. Para retirar a influência do veio no resultado, nos dois primeiros testes (11.732 $\mathrm{t}$ ), as placas com chanfro foram instaladas no primeiro veio e, no terceiro teste $(9.464$ t), no outro veio. Não foram reportadas ocorrências operacionais no lingotamento, laminação a quente ou decapagem relacionadas às placas com chanfro. Após estes três testes, as placas do molde com chanfro não apresentaram danos ou desgaste significativo e por isso elas continuaram a ser utilizadas.

\subsection{Solidificação Dentro do Molde}

Para investigar a influência desta geometria chanfrada na primeira fase da solidificação no molde, foi realizada uma análise metalográfica de duas amostras (com e sem chanfro) de tamanho de $30 \times 30 \mathrm{~mm}$ dos cantos de placas de uma mesma corrida de aço peritético.

As amostras brutas dos cantos das placas estudadas foram cortadas em serra de fita com refrigeração, lixadas com refrigeração até grana 1400 , polidas com diamante em suspensão aquosa de 6,3 e $0,25 \mu \mathrm{m}$, e em alumina 0,05 $\mu \mathrm{m}$. $\mathrm{O}$ ataque metalográfico escolhido foi o Nital $5 \%$ por 2 minutos e Picral $10 \%$ por 3 minutos, e secagem com gás nitrogênio. O microscópio utilizado é um Zeiss, STEMI 2000-C, em aumento de 6X. As amostras obtidas através dessa metodologia são mostradas na figura 4.

Pode ser visto na figura 4(a), que a amostra com canto de $90^{\circ}$ apresenta duas frentes de solidificação que se encontram em uma linha diagonal de $45^{\circ}$. Neste caso, a direção da formação de pele é curvada. A amostra com canto chanfrado na figura 4(b) mostra que a solidificação aconteceu em três frentes de solidificação, em uma forma praticamente radial e mais homogênea. 


\section{$46^{\circ}$}

(a)

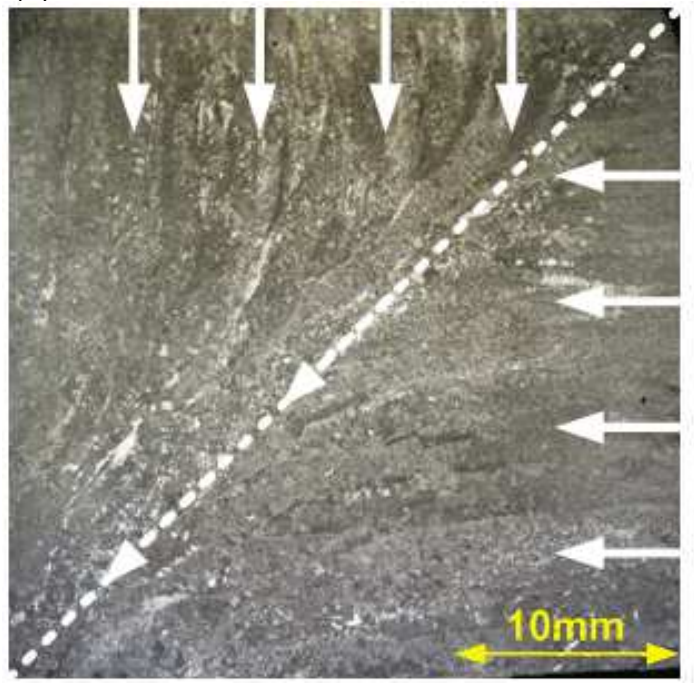

(b)

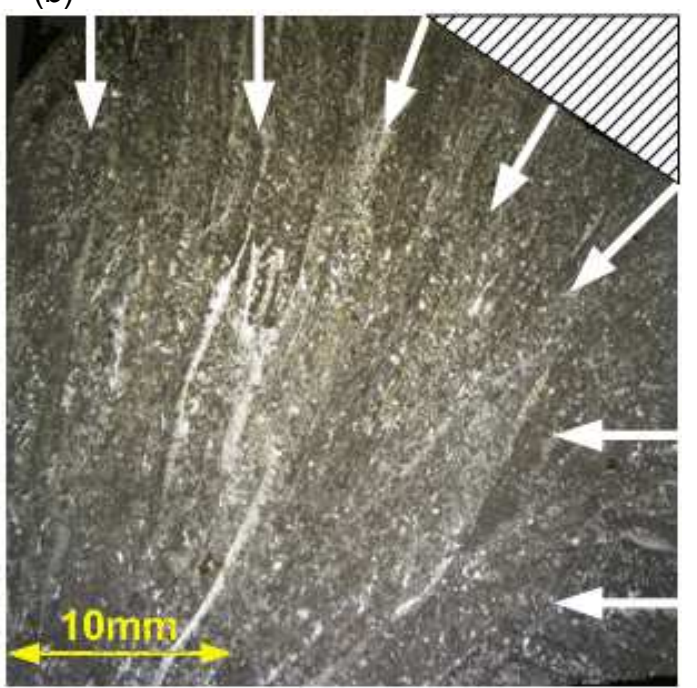

Figura 4. Análise metalográfica da amostra do canto a 90ำ (a) e da amostra do canto com chanfro (b).

\subsection{Resultados da Qualidade}

Os tipos de aço mais suscetíveis para a formação de trincas de cantos são tipicamente os aços ligados de alta e média resistência. Nos três testes conduzidos, $72 \%$ das corridas lingotadas foram de aços de alta e média resistência, sendo $24 \%$ de aços ligados de alta resistência. As distribuições dos grupos de aço e dos graus de resistência são mostradas nas figuras $5(a)$ e (b).

(a)

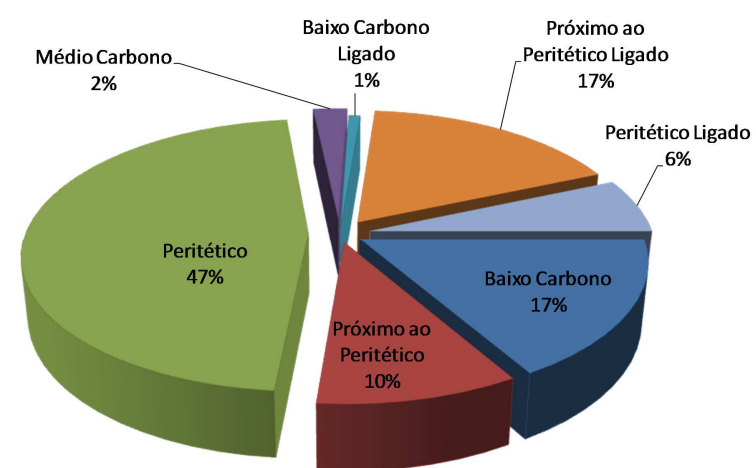

(b)

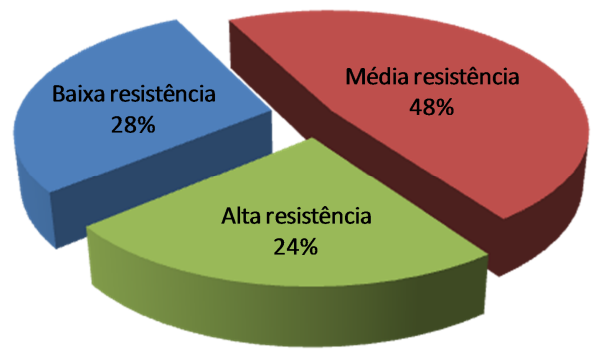

Figura 5. Distribuição dos tipos de aço (a) e dos graus de resistência (b) das placas lingotadas.

A figura 6(a) mostra que $54 \%$ das placas foram produzidas com "Aprovação Direta" na Aciaria (sem escarfagem e inspeção), 8\% com aplicação de "Escarfagem Manual" e inspeção e $36 \%$ com aplicação de "Escarfagem Automática e Inspeção". Conforme a figura 6(b), 27\% das placas foram aplicadas em Bobinas a Quente Decapadas (BQD) ou Bobinas a Frio (BF).

A avaliação da eficácia da aplicação do molde chanfrado em relação ao defeito superficial "Esfoliação Metálica" de borda foi realizada a partir da inspeção visual das bobinas após a decapagem. Deste modo, apenas as placas aplicadas em Bobinas a Quente Decapadas (BQD) e Bobinas a Frio (BF) puderam ser avaliadas. Na inspeção visual é determinada a intensidade do defeito, a posição em relação à largura, a localização quanto à face e comprimento e a extensão (porcentagem da tira afetada pelo defeito). A inspeção visual na decapagem é realizada por dois inspetores (um em cada face da tira) e conta com o auxílio do Parsytec ${ }^{\oplus}$, software de inspeção automática da superfície. 
(a)

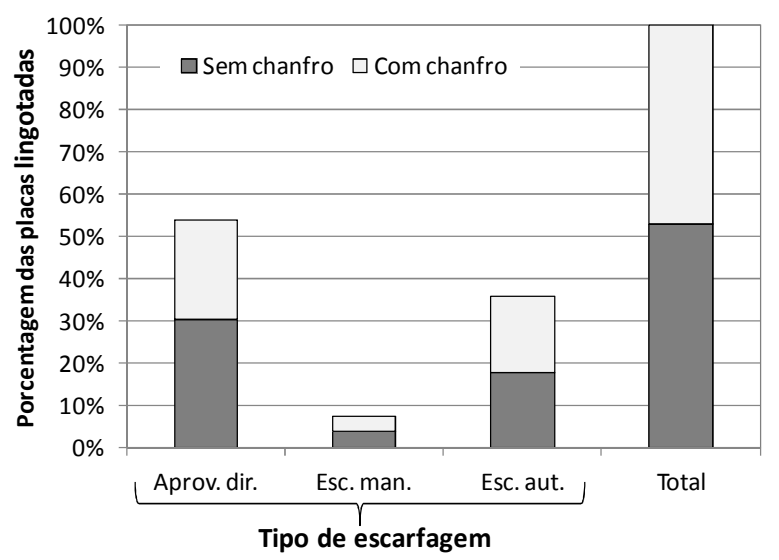

(b)

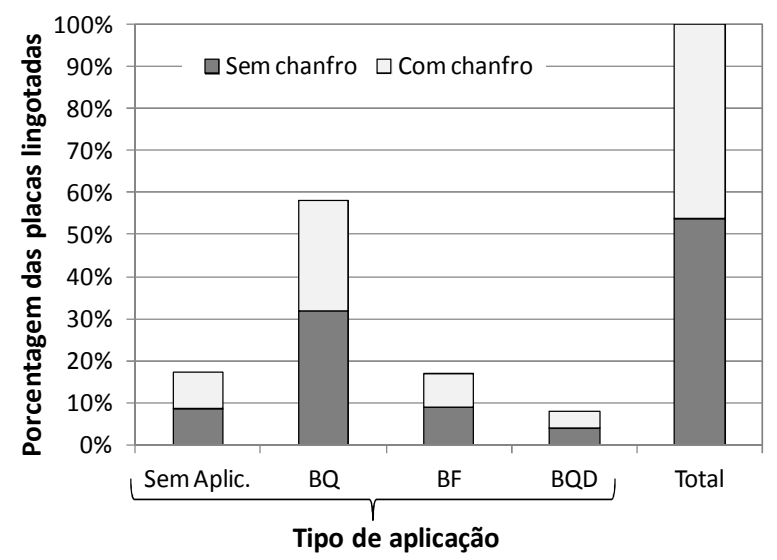

Figura 6. Estratificação das placas lingotadas por tipo de escarfagem (a) e aplicação (b).

Nos três testes, nenhuma das bobinas decapadas (produzidas de placas com e sem chanfro) apresentou "Esfoliação Metálica" em intensidade grave para provocar desvio das mesmas. Para avaliar a eficácia do molde chanfrado apesar da ausência de desvios, foram consideradas as ocorrências de "Esfoliação Metálica" de baixa intensidade, identificadas pelo inspetor da decapagem.

Como já foi mencionado, a intenção da aplicação da geometria de molde chanfrada é a diminuição a ocorrência do defeito "Esfoliação Metálica" nas bordas. A figura 7 mostra o desempenho das placas de molde com chanfro através da porcentagem das bobinas decapadas com ocorrência de "Esfoliação Metálica". A ocorrência de "Esfoliação Metálica" de borda nas bobinas de placas com chanfro foi aproximadamente três vezes menor do que nas bobinas de placas sem chanfro (27\% vs. $73 \%$ ). A aplicação das placas com chanfro não contribuiu para a geração de outros defeitos de superfície, como "Esfoliação Metálica" de centro.

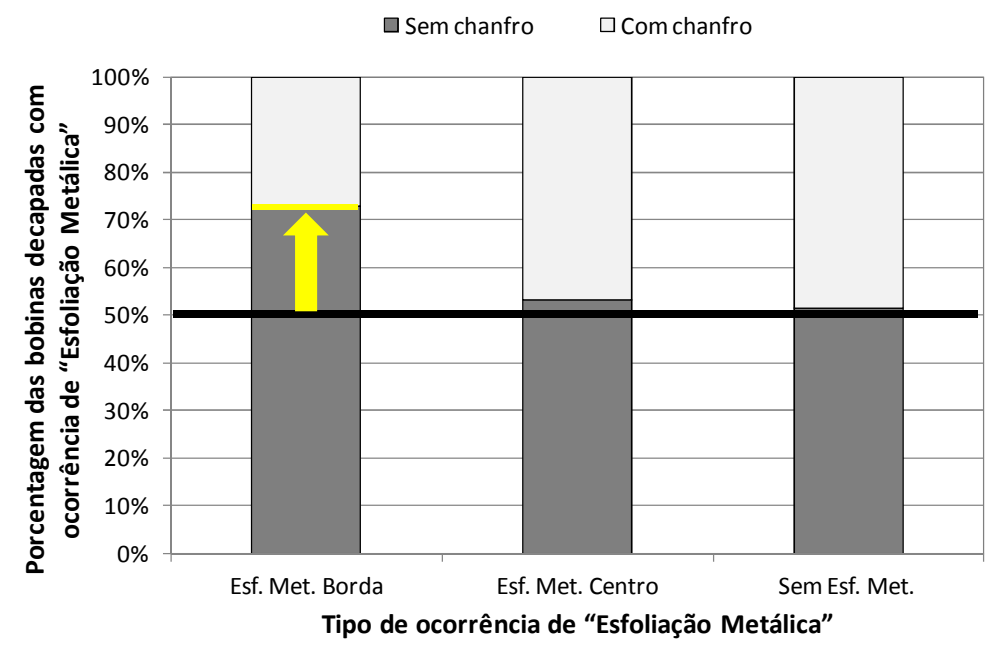

Figura 7. Resultados de qualidade das bobinas BF e BQD.

\section{CONCLUSÃO}

No presente trabalho, o projeto da aplicação das placas laterais do molde com chanfro na Máquina de Lingotamento 4 da Usiminas / Cubatão foi abordado.

Durante a fase inicial de aplicação não foram reportadas ocorrências operacionais no lingotamento, laminação a quente e decapagem relacionadas às placas laterais 
do molde com chanfro. Após dessa fase, as placas laterais aplicadas não apresentaram danos ou desgaste significativo e por isso elas continuaram a ser utilizadas.

Os resultados de qualidade das ocorrências de "Esfoliação Metálica", identificadas na inspeção visual após a decapagem, mostraram uma redução significativa do defeito de "Esfoliação Metálica" de borda. Alem disso, a aplicação das placas estreitas do molde com chanfro não contribuiu para a geração de outros defeitos superficiais.

Diante dos resultados de qualidade positivos, a Máquina de Lingotamento 4 da Usiminas / Cubatão passará a operar de modo padrão com molde chanfrado.

\section{REFERÊNCIAS}

1 Tirolet N, Poelmans K, Mabelly P. Prevention of corner cracks in slab continuous casting. 6th European Conference on Continuous Casting Proc.; Riccione, Italy: Associazione Italiana di Metallurgia (AIM); 2008: 254-266.

2 Qingshen M, Zhonghang J, Li X, Wenbin L, Xiaoshan Y, Yan L. Cause and Measures of Transverse Corner Crack in Hull Structural V-Containing Steel CC Slabs. International Seminar 2005 on Application Technologies of Vanadium in Flat - Rolled Steels Proc.; Suzhou, China: A Vanitec Publication; 2005: 75-78.

3 Derda W, Wiedermann J. Some Aspects of Continuous Casting of Low Carbon Microalloyed Steels with Niobium and Titanium. Archives of Metallurgy and Materials. 2012; 57(1): 303-310.

4 Wimmer F. Special mold slabs in bloom and slab casting. 8th European Conference on Continuous Casting Proc.; Graz, Austria: The Austrian Society for Metallurgy and Materials (ASMET); 2014: 124-131.

5 Patrick B, Thornton SG. Effect of mold and top cooling zone corner to corner transverse and longitudinal cracking in slabs and blooms: Final Report. Luxembourg: DirectorateGeneral Science, Research and Development - Commission of the European Communities Technical Steel Research; 1990. 